65 the author estimates that some 20 per cent fall into this category, while a smaller but still considerable number need alternative work well before their mid-sixties. There are, of course, wide differences between occupations and the report provides some provisional data relating to thirty occupational groups. The Report suggests that an important question is whether an increasingly mechanized industry will be able to provide the kind of work needed by ageing workers and by those who do not wish to retire at 65 . If not, what other social arrangements will be needed to ensure the well-being of the ageing man ?

\section{Staff for Industry and Commerce}

Two important publications dealing with the control and development of staff in industry and commerce have been issued by the Institute of Personnel Management. The first, by E. M. Barling, late director of personnel of the John Lewis Partnership, is concerned with the management of workers whose skills are mainly mental or social rather than manual. Much of the practice described by Miss Barling will be of interest to those dealing with similar problems in large industrial and commercial organizations, Government departments, public corporations, hospitals and scientific establishments. The subjects covered include training and education, pay and incentives, consultation and communications, and welfare amenities. (Pp. 46. London : Institute of Personnel Management, 1959. 4s. 6d.) The second, by F. I. de la P. Garforth, of the Department of Work Study and Staff Training, Engineering and Allied Employers' West of England Association, provides a systematic approach to the provision of supervisors and managers. The subjects covered in the broadsheet include organization charts, staff reviews and appraisals, forecasts of vacancies, recruiting policy, further education and training for staff, job rotation and exchange, and a section on the initiation and operation of a systematic management development policy. (Management Development: a Systematic Approach to the Provision of Supervisors and Managers. Pp. 72. London: Institute of Personnel Management, 1959. I5s.6d.)

\section{I.C.S.U. Review}

THE activities of the International Council of Scientific Unions have greatly expanded during recent years. Joint Commissions have been appointed covering fields of interest eommon to two or more of the constituent unions and other committees have been formed to organize specific programmes of research. The recent International Geophysical Year was initiated and sponsored by the Council through a special committee appointed to supervise the programme. Despite these outstanding achievements, there is still widespread ignorance concerning the organization and activities of the International Council of Scientific Unions. The lack of adequate information concerning its affairs has been felt to be detrimental to the continued growth of the Council. As a step towards remedying this state of affairs, and with the view of encouraging the flow of information between individual unions, the Executive Board of the Council has approved the establishment of a new quarterly journal to be called the I.C.S.U. Review, to provide information to members of the Council and to all who are interested in international co-operation in science, about the activities of the Council and of the scientific unions. The I.C.S.U. Review will contain reports of meetings of the Bureau, the Executive Board, and the General Assembly of the I.C.S.U., information about special activities, reports of some of the more important symposia, reviews of certain publications, special articles on various aspects of international co-operation in science, and announcements about forthcoming meetings, symposia or congresses organized by the unions. In the first issue (May 1959. Pp. i +56 . Subscription 16 florins; 30s.; or 4.50 dollars por volume of four issues. Amsterdam : Elsevier Publishing Co., 1959), Prof. A. von Muralt, treasurer of the International Union of Physiological Sciences and former president of the International Council of Scientific Unions, has written an article entitled "What does ICSU stand for ?". There are other articles on international collaboration in science by L. V. Berkner, on the International Geophysical Year by Prof. Sydney Chapman, on the marine sciences by Roger Revelle, and a review of some aspects of the origins of life considered in the light of the Moscow international symposium of August 1957, by N. W. Pirie. With the increasing importance of international co-operation in science in recent years, and the growing status of the International Council of Scientific Unions as an essential part of the organization of scientific activities on a world-wide scale, the I.C.S.U. Review will undoubtedly fill an important niche in the literature of science, and will find a place on the shelves of all scientific libraries and information services.

\section{Russian Journal of Inorganic Chemistry}

A translation of the Russian Zhurnal Neorganicheskoi Khimii, the only Russian journal devoted exclusively to inorganic chemistry, is being published by the Chemical Society under the title Russian Journal of Inorganic Chemistry. In an introduction to the first number, the President of the Chemical Society states that it marks a further step in a plan to make Russian chemical literature more generally available. Many chemists have become aware of their loss in being unable to read in the original the numerous important scientific papers now being published in the U.S.S.R. Although increasing attention is being paid to the teaching of Russian, the need for English translations will inevitably persist for a long time. The publication has been made possible by the farsighted support of the Department of Scientific and Industrial Research. The Council of the Chemical Society believes that the venture will not only be of direct value to many research workers, but that it will serve to strengthen still further the sense of international partnership in the advancement of chemical science. The translation is by experts. The distributors are Cleaver-Hume Press, Ltd., 31 Wright's Lane, London, W.8. The ordinary subseription rate is $£ 30$ (90.00 dollars in the United States) per annum, to libraries of universities and technical colleges $£ 2210$ s. (67.50 dollars in the United States), in both cases inclusive of postage. The first number has 105 pages in the large format of the Journal of the Chemical Society and includes thirty-nine papers and eight brief communications, in all cases in full. The topies cover a wide range of interests in inorganic chemistry, some of the papers bordering on physical chemistry, and the standard is high. As indicating the general interest of the journal, mention may be made of one paper in which $\alpha$-MnS is shown to be photo-oxidized during the recording of the powder $\mathrm{X}$-ray pattern, and the published data on $\alpha$-MnS are wrong. 